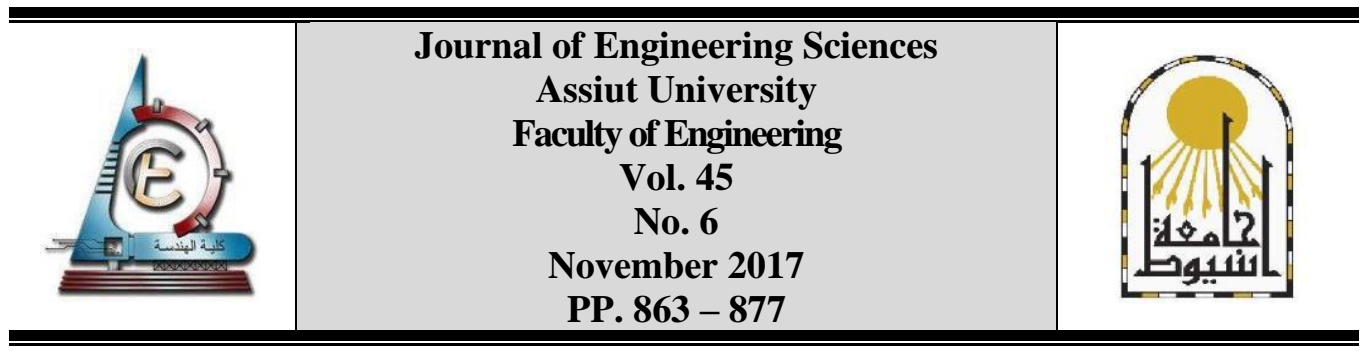

\title{
PROCESS ORIENTED GUIDED EXPERIENTIAL LEARNING AS AN INNOVATIVE TEACHING METHOD IN LIGHTING EDUCATION IN ARCHITECTURE
}

\author{
Ashraf Ali Ibrahim Nessim \\ Architectural Engineering Department, Faculty of Engineering, Ain Shams University. \\ Email: a.nessim@eng.asu.edu.eg
}

Received 11 October 2017; Accepted 15 November 2017

\begin{abstract}
As acknowledged, exterior lighting brings its own unique elements to the nighttime scene. The exterior lighting designer's challenge is to define and enhance the building appearance, thus adding ambiance to the exterior night scene.

This pedagogical study aims at evaluating the experience of the application of Experiential learning method in lighting education in architecture as it presents the lessons learned during and the outcomes of the International Lighting Design Workshop held in Kronach, Germany. The workshop is part of the preparations of a lighting festival held annually called "KRONACH leuchtet" or "Kronach in Lights". The workshop covers both theoretical parts and practical experiences. The workshop targets undergraduate and postgraduate students. To achieve the aim of the workshop, the participants were involved in a process oriented "Experiential Learning" approach. The use of modern and innovative educational technology and Experiential learning in lighting education is valuable in conducting efficient training and professional induction of participants. The detected findings of this paper could help those involved in teaching lighting courses as the experience of using the Experiential Approach method shows promising character of its application in the lighting education. It can be used to improve the communication skills, critical thinking and problem solving skills of participants. Meanwhile, the paper offers relevant methods of introducing future architects to the study of lighting in architecture.
\end{abstract}

Keywords: Lighting design, Lighting Education, Experiential learning, Process oriented, Innovative teaching, Creative lighting, Architecture.

\section{Introduction}

Nowadays, engineering applications require graduates to develop and update their knowledge in professional life in a continuous manner since technology is promptly changing and becoming more complex. Unfortunately, due to lack of knowledge and training sessions, trial and error method is commonly used in most of the applications by newly graduated engineers. However, this method could be a cause of economic losses, and undermines occupational safety and health at work especially when related to lighting and electrical applications [11]. Meanwhile, and after examining the prevailing/conventional lighting education methods, it was found that current teaching practices in lighting design are focused 
on didactic lectures. This method minimizes the understanding, recalling of the subject and hence disengages the students from the learning process. Due to this, the application of knowledge and problem solving skills among students are greatly reduced [10].

However, the architectural lighting design process is based on a creative phase where creativity is valued. According to [9], the literature on creativity is vivid and stimulates the decision-making process but these tools are hardly present in the lighting design process. In recent years, universities and architecture faculties in particular, have made important efforts to improve architectural lighting education. The goals of applying new ways of teaching architectural lighting are mainly concerned with enriching the pure artistic vision of architecture at night using lighting, through the insertion of scientific knowledge and applying practical applications. This can be done by engaging the student in experimental learning of the lighting design process [9].

As a matter of fact, learning is a complicated concept as everyone is unique in their own way, and learns in their own way as well. Till few years ago, traditional learning methods were followed. Currently, many innovative teaching methods are available and varies from blended learning, e-learning, flipped learning, interactive learning, adaptive learning, experiential learning or learning by doing, brainstorming, etc... [4].

After examining the various innovative learning methods, Brainstorming is probably the best-known method to stimulate creativity, where experts from various fields put their ideas forward without prior judgment. There are basic rules to Brainstorming: Focus on quantity; No criticism; Unusual ideas are welcome since they combine and improve ideas.

Brainstorming is a technique by which a group of individuals attempt to find answers for a specific challenge by building-up ideas spontaneously. Meanwhile, experiential learning contrasts with learning from observing others demonstrate reading, or listening to others' coaching's or instructions. In fact, experiential learning implies learning from experiences resulting directly from one's personal trials [4]. Experiential learning is recommended as a way to increase critical thinking and students' engagement, enhance theory-informed practice, increase readiness, and improve multicultural understanding for students participating in international workshops [2]. Finally, and from the participants' perspective, experiential learning can be beneficial but apprehensive. Consequently, and in order to maximize the benefits of experiential learning projects, particpants' need to have confidence in their abilities [3].

This paper shall focus on the learning methods proven to be useful in teaching lighting in universities, and architecture faculties in particular, as an approach to graduate a new generation of architects specialized in exterior lighting.

\subsection{The main objective}

This paper aims at presenting the lessons learned and the work/output of the students that participated in the $5^{\text {th }}$ and $6^{\text {th }}$ International Lighting Design Workshop "Kronach in Lights" in Kronach, Germany. Contributing in the workshop represented a unique opportunity for participants to deepen their knowledge about possibilities to work with light and practice their skill while working on full-scale projects. The challenge was to learn about the methods of lighting design by preparing impressive scenery at night.

The objective of this paper is twofold; 
Ashraf Ali Ibrahim Nessim, Process oriented guided experiential learning as an innovative .......

First: How the analyses of the direct comparison on the student's performance before and after the workshop reflect the importance of using active learning and experiential design methods in lighting education in higher education.

Second: How to allow undergraduate and postgraduate participants to have a maximum understanding of the concepts and methods of lighting design in architecture.

\subsection{Methodology}

The two investigated case studies were the International Lighting Design Workshop "Kronach in Lights" held in Kronach, Germany in 2016 and 2017 consequently. The population for those case studies included about 30 undergraduate and postgraduate participants, from different nationalities, divided into five groups. Each group was led by a group head. From the five group heads, two of them are Ph.D. holders specialized in lighting and three professional lighting designers'. The groups were supported by five specialists for technical support and three coordinators from the organizing association of the workshop and the lighting festival.

The objective of this paper is achieved through the analysis of the two workshops. The analysis is done on four main stages as follows:

At first, the background of the workshop was explored and its structure was revealed.

Secondly, the experiential learning theory was deliberated.

Thirdly, the lighting workshop goals were clarified.

Finally, and after the students' participation in the workshop, a questionnaire was administered to evaluate the performance of students \& active learning process and workshop outcomes.

\section{Analysis of theactive learning process and experiential designmethod used in the workshops}

This section aims at giving a brief background about the workshop and the experiential design method that was applied during the workshop. It is divided into two parts. The first part highlights the workshop background and its structure. It gives a brief description of the workshop history, duration, activities and participants. The second part gives a brief overview of the experiential learning theory and highlights the experiential learning cycle.

\subsection{Workshop background and structure}

The annual light festival in Kronach takes place since 2006 and the International Lighting Design Workshop started since 2012. "Kronach in Lights" starts with an architectural lighting design workshop that is part of the light festival. The participants in the workshop are lighting designers, undergraduate and postgraduate architecture students. The workshop week is divided into a theoretical and craft parts. In the morning there are sessions for planning and design. In the afternoon, until late at night, the participants gain much hands-on experience by building and testing settings on the buildings and in the streets. This workshop week is considered a unique opportunity for participants to deepen their knowledge about possibilities to work with light and practice their skill while working on full-scale projects. The challenge is to learn about the methods of lighting design, by preparing an impressive scenery.

Students from the following universities participated each year in the workshop: 
a. Hochschule Wismar, University of Applied Sciences Technology, Business and Design, Wismar, Germany.

b. Politecnico di Torino, Dipartimento di Architettura e Design, Torino, Italy.

c. Ain Shams University, Faculty of Engineering, Credit Hours Engineering Program, Cairo, Egypt.

d. Coburg University of Applied Sciences and Arts, Coburg, Germany.

e. HTWK Leipzig, Leipzig, Germany.

The participants from the above institutions are divided among five groups. Each group is responsible for creating its own theme and installing the lighting installations. Fig [1] shows the location five lighting installations that were designed and installed by the workshop groups in the $6^{\text {th }}$ International Lighting Design Workshop “Kronach in Lights” in Kronach, Germany 2017.
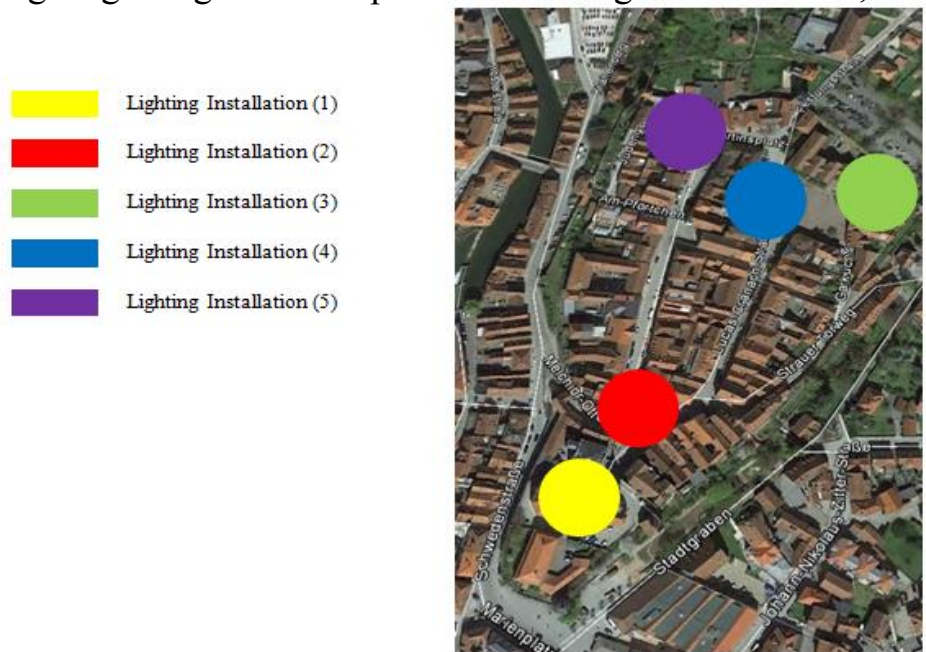

Fig. 1. Layout of "Upper Town" in Kronach, Germany showing the workshop zones and the different lighting installations (Source: Author)

\subsection{Overview of the experiential learning theory}

According to [8], linking the theory and its practical applications has been in focus for several years whether on educational level or training agendas. Traditionally, instructor's goal is to demonstrate to learners how to apply theory which they have learned in a different context to simulate aspects of the real world experience [8]. It is common for modules to be called as either practical or theoretical: as either involving doing or involving thinking. As indicated in the Learning Pyramid in Fig [2], the average retention rates after 24 hours for lecturing method is only $5 \%$ while for Practice by doing method it can reach $75 \%$.

The Learning Pyramid

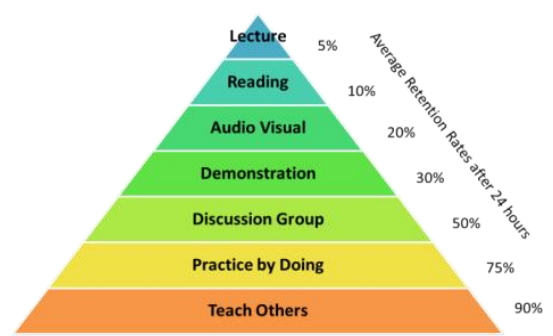

Fig. 2. The learning Pyramid showing the average retention rates after 24 hours for different learning methods. [Source: http://www.basicknowledge101.com/subjects/learningstyles.html ] 
Ashraf Ali Ibrahim Nessim, Process oriented guided experiential learning as an innovative .......

Experiential learning theory can be defined as follow: "the process whereby knowledge is created through the transformation of experience". According to Kolb's theory, developing new concepts is motivated and gained by new experiences [6].

\subsubsection{The experiential learning cycle}

Kolb identified the experiential learning theory as a cycle consisting of four stages. The four stages are: Concrete Experience, Reflective Observation, Abstract Conceptualization, and Active Experimentation. Accordingly, the learner should pass by all stages as shown in Fig [3].

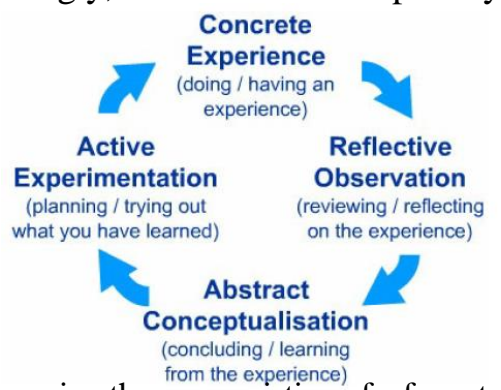

Fig. 3. The experiential learning theory consisting of a four stages represented in a full cycle [2]

In order to experience a successful experiential learning process, the participant has to experience Kolb's full cycle and progress through the four different stages. The cycle starts by having a concrete experience. Then the participant makes observations of and reflections on that experience. Afterwards, the participant starts forming abstract concepts through analysis and generalization of conclusions. Finally, the hypothesis is tested in future situations thus resulting in new experiences. Each stage is considered an integrated process. The different stages are mutually supportive and each stage feeds into the next. However, successful experiential learning occurs when the participant accomplishes all four stages of the process sequentially. Accordingly, none of the cycle stages is effective on its own.

\subsection{Application of the experiential learning theory on students' studying lighting in architecture}

The workshop sessions were designed to follow the full cycle of the experiential learning method. All participants had a theoretical background and basic knowledge about exterior lighting and its application on architecture.

As an introduction, the different workshop areas were introduced to participants via a guided tour through the town Fig [4]. The aim of the guided tour was to introduce the participants to the context of the workshop by day which shall have its own reflections on their lighting design concept and applications. Afterwards, students were divided into five groups and started brainstorming their ideas under the supervision and in collaboration with the group head Fig [5]. Group heads played an important role in devising appropriate experiences and facilitating reflections.

At first, participants were involved in an active exploration of experience. Experience was used to test out ideas and assumptions rather than to obtain practice passively. Accordingly, participants' were engaged in testing the luminaires indoors to grasp a hands on the performance of each luminaire type Fig [6] and testing techniques outdoors to compare the result and fine tune the experience Fig [7]. All participants were committed to the process of exploring and learning independently from the group head. 


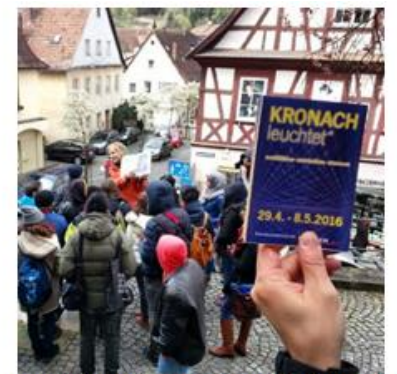

Fig. 4. Introducing the workshop areas to participants via a guided tour to make them familiar with the workshop context. (Source: Author)

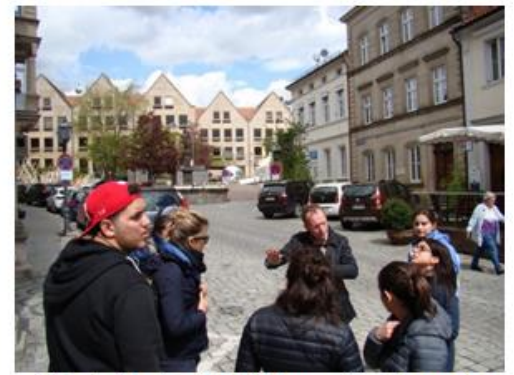

Fig. 5. Sharing initial ideas and brainstorming different concepts among group members under the supervision of the group head. (Source: Author)

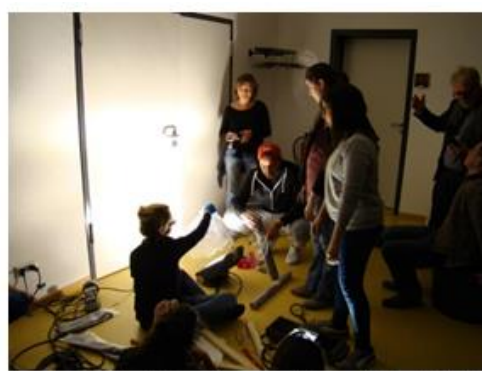

Fig. 6. Participants going through the initial experience to test the luminaire effect indoor. (Source: Author)

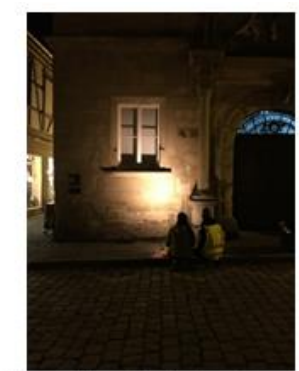

Fig. 7. Participants testing luminaire in real workshop context to grasp a hand on the luminaire performance. (Source: Author)

Secondly, all groups were engaged in reviewing and reflecting upon their experience Fig [8]. This was carried out through daily presentations of the work concept of each group and discussions with all group heads and participants. Participants were urged to selectively reflect on their experience in a critical way rather than taking the experience for granted and assumes that the experience on its own is sufficient.
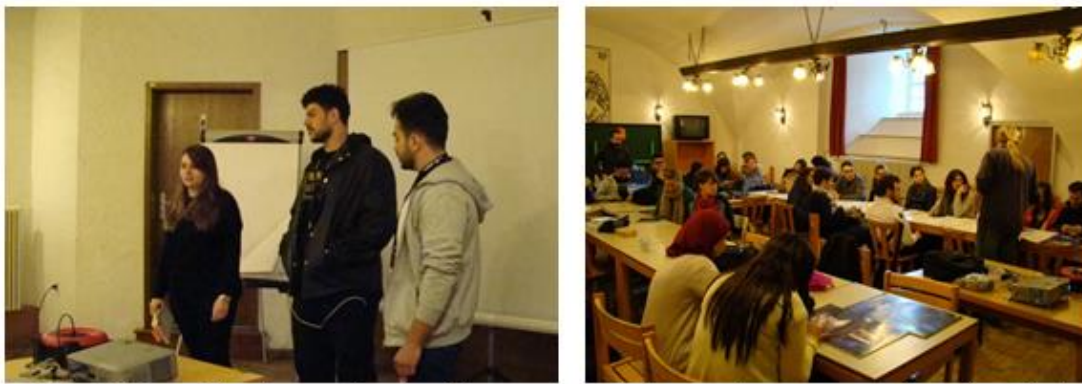

Fig. 8. In a collective session for all groups, participants give a presentation about their group work (above left) and feedback is taken from the discussions of different groups (above right). (Source: Author)

Thirdly, participants were moved to the next stage which was the formation of their abstract lighting concepts in which each group started presenting a solid concept of their work after implementing the comments that the group received from the group heads and other participants Fig [9].

Finally, all groups moved to active experimentation phase in which all groups started implementing their design concept and test their hypothesis on site and practice their skill whilst working on full-scale projects to gain new experiences Fig [10] and Fig [11]. 


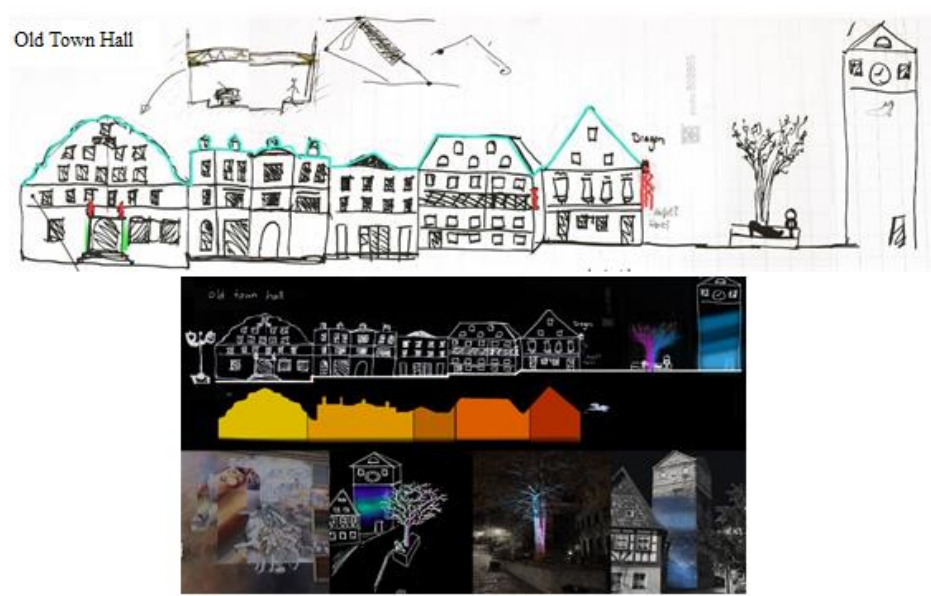

Fig. 9. Lighting concept of Marktplatz group showing the initial freehand sketches of the concept and its elaboration based on gradient light warm color temperature, skyline variation, and tower contrast. (Source: Author)
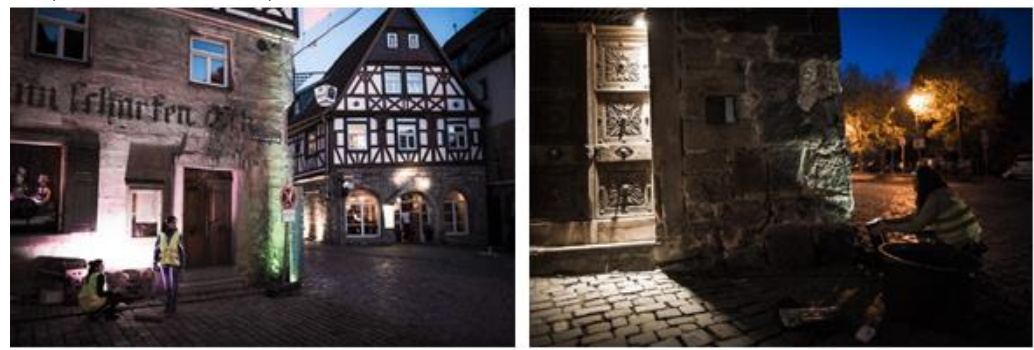

Fig. 10. Students working on their full scale projects to implement their concept and gain new experience. (Source: Author)
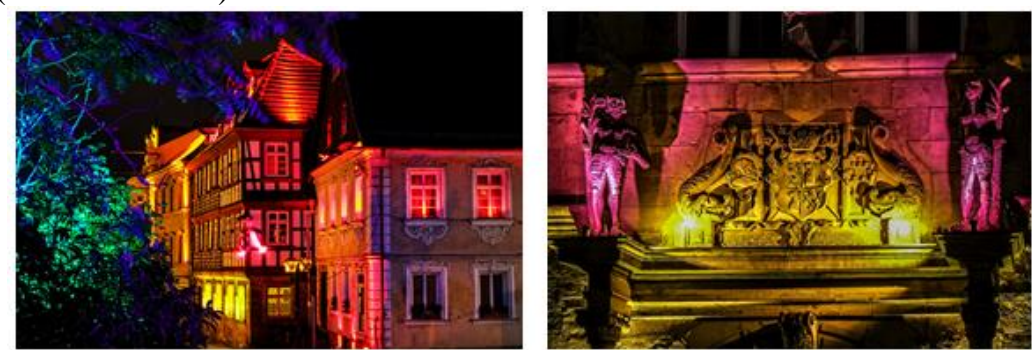

Fig. 11. Part of the work outcome of the workshop participants reflecting innovation and creativity in design. (Source: Author)

\subsection{Evaluation of applying the experiential learning method in teaching lighting in architecture}

After the students' participation in the workshop, a multidimensional survey in the form of a questionnaire was administered to evaluate the performance of students, active learning process and workshop outcomes. The two purposes of the questionnaire were to (a) determine whether the activity enhanced students' understanding of lighting-related topics and (b) determine whether the experiential learning format was effective in teaching and learning of exterior lighting in architecture. The questionnaire was divided into five main sections as follows:

- Section (I): Evaluation of the Theoretical Learning Methods in Practical Courses;

- Section (II): Evaluation of the Experiential Learning Experience;

- Section (III): Evaluation of the Workshop; 
- Section (IV): Evaluation of the Group work and the Social Experience; and

- Section (V): Evaluation of the Workshop Outcomes.

Participants in the questionnaire were selected if they met the following inclusion criteria as (a) students enrolled in an undergraduate or postgraduate program in disciplines related to lighting and architecture; and (b) currently or previously involved in an internship or site training related to lighting. A total of 28 surveys were distributed to students via email and 22 were completed resulting in a $78.5 \%$ response rate. Detailed analysis of the students' evaluation of the different aspects of the workshop can be found in the Results section below.

\section{Analysis of the results}

Results indicated that the workshop achieved experiential learning goals, in that students agreed that they better understood the real-life applications of the concepts, that their interest in the topic area had been stirred, and that they were more likely to recall what they learned from the experiential learning process than they would from normal classroom learning activities. Participants' also agreed that they were contended with the workshop and that it increased their self-reliance level for future work related to exterior lighting in architecture, landscape and the urban context. Direct comparison between the student's outcomes before and after the workshop in different lighting modules showed that there was a considerable improvement in practical skills that require complex cognitive skills after the participation in the workshop.

Table 1.

shows the response of the 22 participants that reflects their perceptions on learning gains and outcomes of the workshop.

To what degree do you agree with the following statements?

\begin{tabular}{|l|l|l|l|l|l|}
\hline \multicolumn{5}{|c|}{ Level (\%) } \\
\hline 1 & 2 & 3 & 4 & 5 & 6 \\
\hline
\end{tabular}

Section (I): Evaluation of the Theoretical Learning Methods in Practical Courses

\begin{tabular}{|c|l|c|c|c|c|c|c|}
\hline 1 & $\begin{array}{l}\text { Theoretical lectures only helped me understand lighting } \\
\text { applications better. }\end{array}$ & 86 & 10 & 4 & 0 & 0 & 0 \\
\hline 2 & $\begin{array}{l}\text { I can learn and apply what I have been taught in } \\
\text { theoretical lectures on lighting without any previous } \\
\text { practical application. }\end{array}$ & 0 & 86 & 14 & 0 & 0 & 0 \\
\hline
\end{tabular}

Section (II): Evaluation of the Experiential Learning Experience

\begin{tabular}{|l|l|c|c|c|c|c|c|}
\hline 3 & $\begin{array}{l}\text { I can identify the learning experience within the } \\
\text { workshop. }\end{array}$ & 0 & 0 & 0 & 0 & 10 & 90 \\
\hline 4 & The workshop did not enhance the learning experience. & 90 & 10 & 0 & 0 & 0 & 0 \\
\hline 5 & $\begin{array}{l}\text { The learning experience provided in the workshop } \\
\text { forced me to do more than just listen. }\end{array}$ & 0 & 0 & 0 & 0 & 5 & 95 \\
\hline 6 & I was stimulated from what I learned in the workshop. & 0 & 0 & 0 & 0 & 14 & 86 \\
\hline 7 & I experienced real-life problems during the workshop. & 0 & 0 & 0 & 0 & 0 & 100 \\
\hline Section (III): Evaluation of the Workshop & $\begin{array}{l}\text { The workshop was presented to me in a challenging } \\
\text { way. }\end{array}$ & 0 & 0 & 0 & 10 & 13 & 77 \\
\hline 9 & The introductory sessions of the workshop helped me to & 0 & 0 & 0 & 5 & 5 & 90 \\
\hline
\end{tabular}


Ashraf Ali Ibrahim Nessim, Process oriented guided experiential learning as an innovative .......

\begin{tabular}{|l|l|c|c|c|c|c|c|}
\hline \multicolumn{2}{|l|}{ To what degree do you agree with the following statements? } & \multicolumn{5}{|c|}{ Level (\%) } \\
\cline { 2 - 8 } & $\mathbf{1}$ & $\mathbf{2}$ & $\mathbf{3}$ & $\mathbf{4}$ & $\mathbf{5}$ & $\mathbf{6}$ \\
\hline 10 & prepare for the workshop activities. & & & & & & \\
\hline 11 & $\begin{array}{l}\text { I felt like I was an active part of the workshop. } \\
\text { past experiences. }\end{array}$ & 0 & 0 & 0 & 4 & 10 & 86 \\
\hline 12 & The workshop made sense to me. & 0 & 0 & 0 & 0 & 32 & 68 \\
\hline 13 & This workshop was applicable to me and my interests. & 0 & 0 & 0 & 0 & 23 & 77 \\
\hline 14 & I found value in this workshop. & 0 & 0 & 0 & 0 & 10 & 90 \\
\hline 15 & This workshop had nothing to do with me. & 100 & 0 & 0 & 0 & 0 & 0 \\
\hline 16 & This workshop will not be useful to me in the future. & 100 & 0 & 0 & 0 & 0 & 0 \\
\hline 17 & I expect to work on projects similar to the workshop. & 0 & 0 & 0 & 4 & 18 & 68 \\
\hline 18 & This workshop was enjoyable to me. & 0 & 0 & 0 & 0 & 0 & 100 \\
\hline 19 & I found this workshop boring. & 100 & 0 & 0 & 0 & 0 & 0 \\
\hline Section (IV): Evaluation of the Group work and the Social Experience & & & \\
\hline 20 & $\begin{array}{l}\text { The workshop obliged me to interact with other } \\
\text { participants and group heads. }\end{array}$ & 0 & 0 & 0 & 0 & 10 & 90 \\
\hline 21 & $\begin{array}{l}\text { Working with peers from different backgrounds \& } \\
\text { nationalities helped me understand and elaborate } \\
\text { concepts. }\end{array}$ & 0 & 0 & 0 & 5 & 18 & 77 \\
\hline 22 & $\begin{array}{l}\text { Working with peers helped to solve complicated } \\
\text { problems. }\end{array}$ & 0 & 0 & 0 & 4 & 6 & 90 \\
\hline 23 & $\begin{array}{l}\text { Working with peers improved the skill of problem } \\
\text { solving. }\end{array}$ & 0 & 0 & 0 & 5 & 9 & 86 \\
\hline 24 & $\begin{array}{l}\text { Working in groups made me less likely to give up on } \\
\text { difficult problems. }\end{array}$ & 0 & 0 & 0 & 0 & 14 & 86 \\
\hline
\end{tabular}

Table 1.

The questionnaire distributed among the 28 participants' aimed at evaluating the workshop and the experiential learning method applied in teaching lighting in architecture. Responses received from 22 participants are shown above and indicates a positive experience.

\begin{tabular}{|l|l|l|l|l|l|l|l|}
\hline \multicolumn{6}{|l|}{ Section (V): Evaluation of the Workshop Outcomes } \\
\hline 25 & $\begin{array}{l}\text { The activities in the workshop helped me better understand } \\
\text { the subject. }\end{array}$ & 0 & 0 & 0 & 0 & 10 & 90 \\
\hline 26 & This workshop will help me make better lighting designs. & 0 & 0 & 0 & 0 & 5 & 95 \\
\hline 27 & $\begin{array}{l}\text { Given feedback on workshop activities helped me to } \\
\text { understand the lighting concepts and applications. }\end{array}$ & 0 & 0 & 0 & 5 & 95 \\
\hline 28 & $\begin{array}{l}\text { I believe the workshop has prepared me for other } \\
\text { experiences. }\end{array}$ & 0 & 0 & 0 & 0 & 14 & 86 \\
\hline 29 & $\begin{array}{l}\text { I can think of tangible ways to make use of this workshop } \\
\text { into future practice. }\end{array}$ & 0 & 0 & 0 & 5 & 9 & 86 \\
\hline 30 & $\begin{array}{l}\text { I will continue to use what I am being taught after the } \\
\text { workshop has ended. }\end{array}$ & 0 & 0 & 0 & 0 & 27 & 73 \\
\hline
\end{tabular}

1. Strongly Disagree / 2. Disagree / 3. Somewhat Disagree / 4. Neither Agree nor Disagree / 5. Somewhat Agree / 6. Strongly Agree 
The following sections present a detailed analysis of the participants' evaluation of the different aspects related to the workshop:

- Section (I): Evaluation of the Theoretical Learning Methods in Practical Courses.

Fig [12] illustrates that $86 \%$ of the participants strongly agreed that the theoretical lectures only are not enough to understand the lighting applications and that they need previous practical application to improve their learning in the lighting courses.

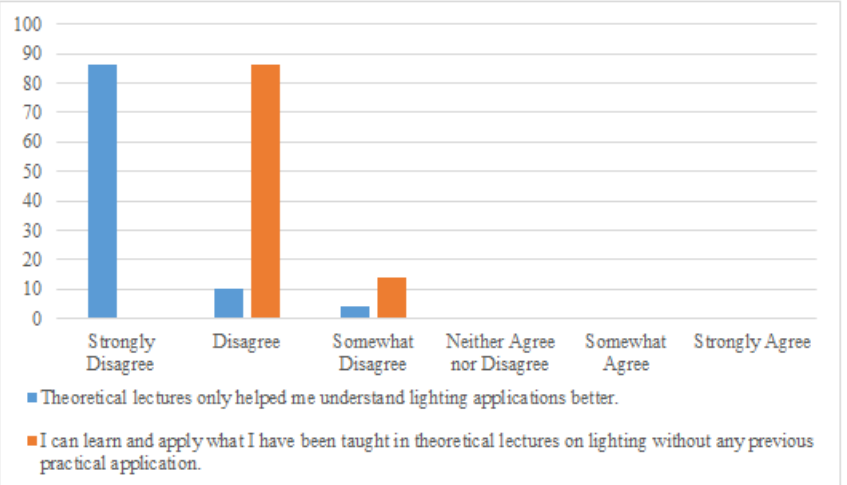

Fig. 12. Students evaluation of the theoretical learning methods in practical courses.

- Section (II): Evaluation of the Experiential Learning Experience.

Fig [13] demonstrates that $90 \%$ of the participants identified the experiential learning experience carried out during the workshop and that the workshop enhanced their learning experience. $95 \%$ of the participants reported that the learning experience forced them to be active contributors. In addition, $86 \%$ of the participants were stimulated from what they learned in the workshop. Furthermore, $100 \%$ of the participants indicated that they experienced real-life problems during the workshop.

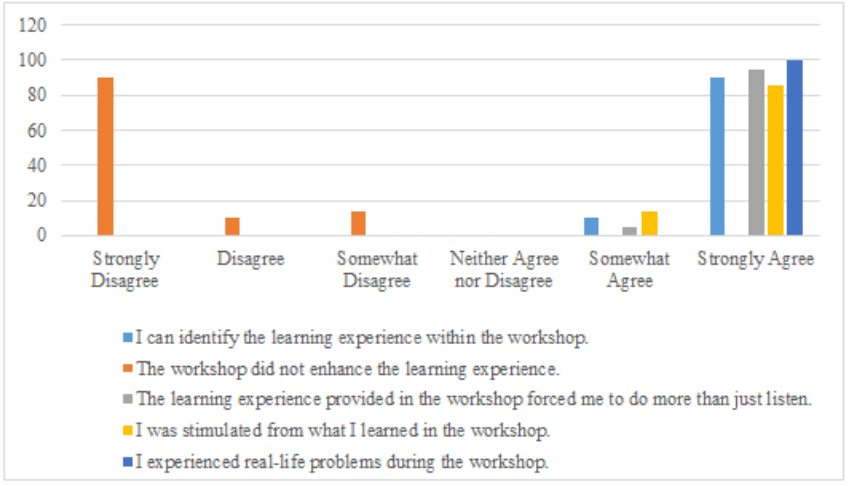

Fig. 13. Students evaluation of the experiential learning experience.

- Section (III): Evaluation of the Workshop.

Fig [14] shows that $77 \%$ of the participants agreed that the workshop was presented to them in a challenging way and $90 \%$ reported that the introductory sessions of the workshop helped them to prepare well for the workshop activities. Meanwhile, $68 \%$ of the participants reported that the group heads encouraged them to share their ideas and past experiences while $90 \%$ found the high value of the workshop related to the exterior lighting design and that it shall be useful to them in their future applications. In addition, 
Ashraf Ali Ibrahim Nessim, Process oriented guided experiential learning as an innovative .......

$68 \%$ of the participants expected to work on similar lighting installations carried out during the workshop. Furthermore, 100\% agreed that the experience was enjoyable to them.

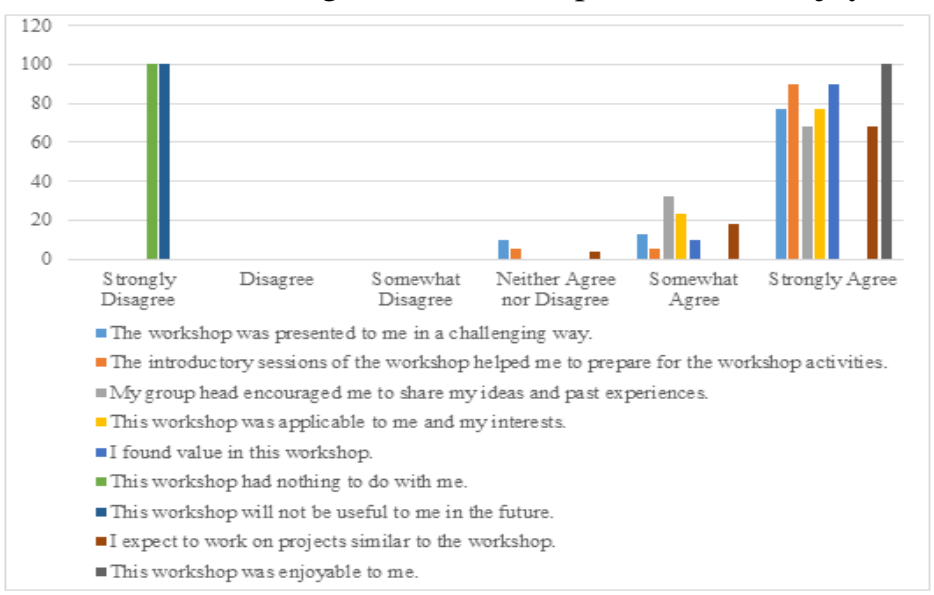

Fig. 14. Students evaluation of the workshop.

- Section (IV): Evaluation of the Group work and the Social Experience.

Fig [15] illustrates that $90 \%$ of the participants were obliged to interact with other participants and group heads and that they were pleased of such experience. $77 \%$ of the participants reported that working with peers from different backgrounds and nationalities helped them to understand and elaborate exterior lighting concepts better. In addition, $90 \%$ agreed that working with peers helped them to solve complicated problems. Meanwhile, $86 \%$ expressed that working with peers improved their skill related to problem solving and made them less likely to give up on difficult problems.

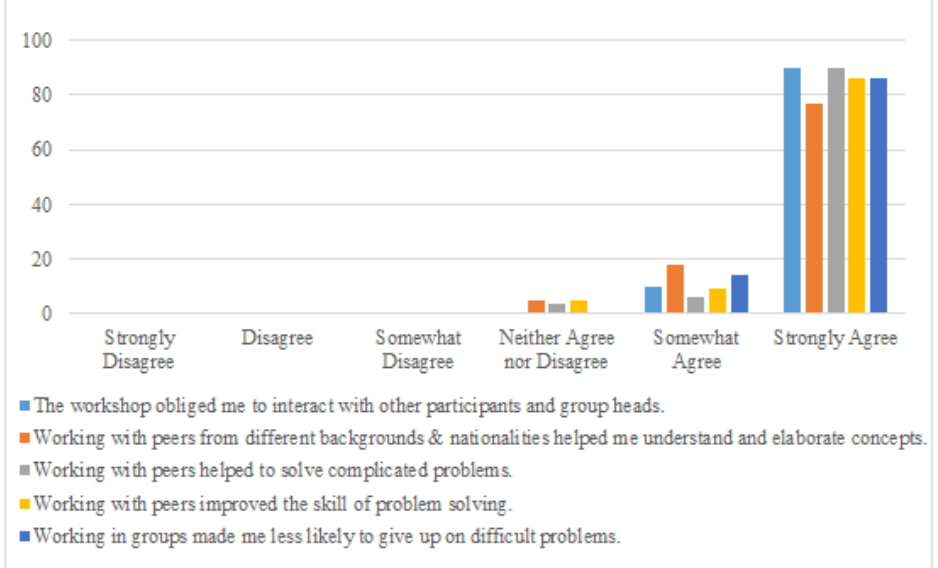

Fig. 15. Students evaluation of the group work and social experience.

- Section (V): Evaluation of the Workshop Outcomes.

Fig [16] demonstrates that $90 \%$ of the participants reported that the activities in the workshop helped them to understand the subject better. $95 \%$ predicted that the workshop shall help them make better lighting designs in their future and that the given feedback on workshop activities helped them to understand the lighting concepts and applications. In addition, $86 \%$ believed that the workshop has prepared them well for other similar experiences and that they 
can think of tangible ways to make use of this workshop during their future practice. Finally, $73 \%$ will continue to use what they were taught after the workshop has ended.

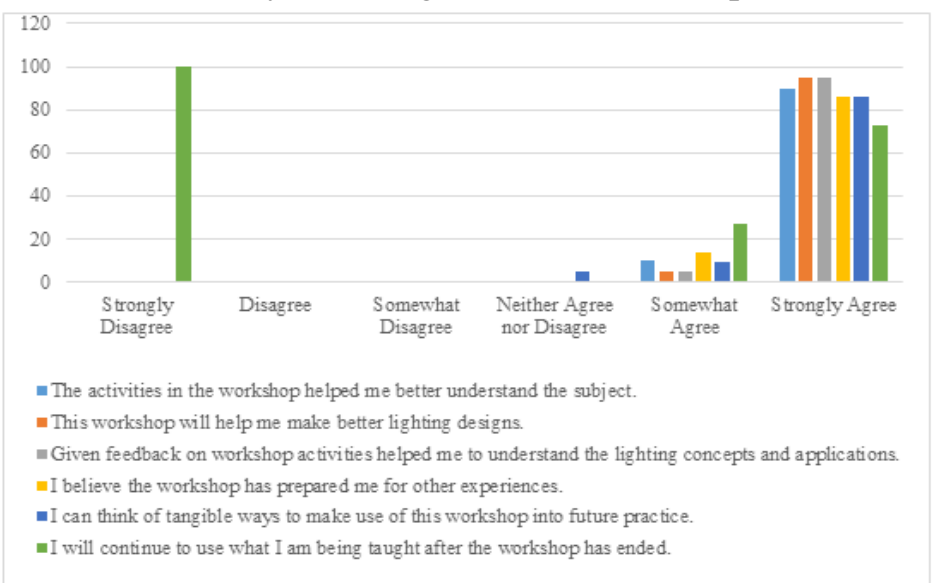

Fig. 16. Students evaluation of the workshop outcomes.

As a final note, almost all the students felt confident regarding the understanding of the lighting concepts and applying it in the urban context after the workshop. Students expressed that they learned better when they were actively engaged in the structured learning format during the workshop, which improved their concept construction and understanding. Majority of the participants reported that they developed greater confidence in designing and implementing their lighting themes and that they felt that feedback given during the workshop helped them to acquire complete knowledge about the subject and made them connect it to prior understandings. This gave them the ability to extend their knowledge base with new concepts and it also created a rich learning environment among them. Most of the participants found that their participation in the workshop transformed them into self-directed learners.

\section{Discussion}

It was found that lighting workshops are ideally suited for teaching lighting in architecture among architecture students. The outcome of the students work after the participation in the workshop was significantly better when compared with traditional classes. The level of knowledge, the development of practical skills and addressing new problems in lighting poses a difficult task for the students. Table $\mathbf{2}$ identifies the different goals of the workshop. It is set by incorporating Blooms levels in exploration [1], concept creation and applications into the workshop. The workshop aims at creating a positive accountable individual, providing mutual support of learning, promoting collaborate skills, and encouraging self-assessment, which was explained as five elements of cooperative learning in groups as showcased by Johnson et al. [7] and described by Hanson [5]. 
Ashraf Ali Ibrahim Nessim, Process oriented guided experiential learning as an innovative .......

\section{Table 2.}

Lighting workshop goals

\begin{tabular}{|c|c|c|c|}
\hline Cognitive & Affective & Social & Lifelong learning \\
\hline 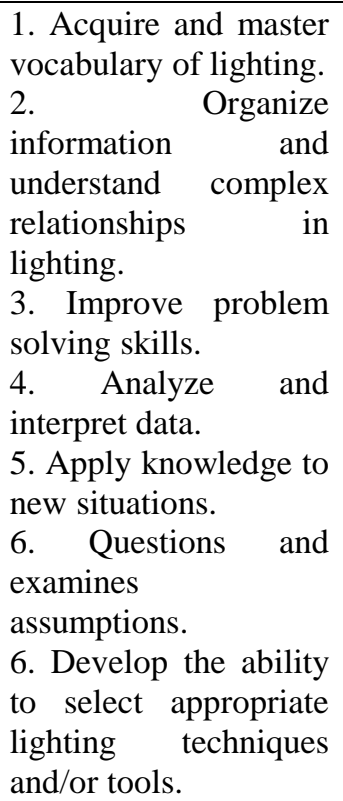 & $\begin{array}{l}\text { 1. Obtain a belief in } \\
\text { one's ability to learn } \\
\text { and apply the material. } \\
\text { 2. Advance } \\
\text { intellectual, tolerance } \\
\text { and integrity. } \\
\text { 3. Set personal goals } \\
\text { for improvement. }\end{array}$ & $\begin{array}{l}\text { 1. Work cooperatively } \\
\text { and demonstrate } \\
\text { commitment to a } \\
\text { group. } \\
\text { 2. Listen to and learn } \\
\text { from } \\
\text { Peers. } \\
\text { 3. Value others work. }\end{array}$ & 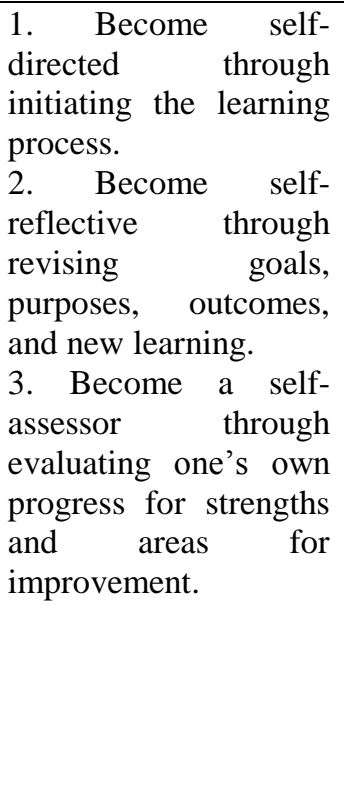 \\
\hline
\end{tabular}

\section{Conclusion}

During the workshop and in the process of the project implementation, the participants were involved into the solution of problems close to professional ones. Such experience helped to deepen the learning process and to encourage participants to be creative. Use of the experiential learning method allowed participants to learn the architectural lighting discipline more effectively and deeply to form a systematic approach for research work and to develop practical skills. The use of modern educational technology and experiential learning in lighting education is particularly important, as they can be used to conduct effective training and professional orientation of participants.

The implementation of experiential learning in teaching lighting in architecture classes has been highly successful as evidenced by student's performance, workshop outcomes, and their perception in acquiring higher order cognitive, social and affective skills. These skills would benefit the students greatly in their future professional lives.

"Experiential Learning" is useful to:

- practice different skills in safe environments;

- illustrate theory by doing;

- develop interpersonal skills;

- increase personal participation in learning and enliven end product;

- derive general principles from examples;

- prepare participants for work experience; and

- Focus attention on practices which are hard or impossible to provide in any other way. 


\section{Recommendations}

The use of experiential learning method is important to provide effective training and professional orientation of participants. This paper recommends the following:

- increasing the awareness of architectural students and professionals of the exterior lighting topic as it reveals a new image for the building and the city during nighttime;

- implementing active learning methods (i.e. experiential learning) in practical courses in the undergraduate curriculum in general and in architectural studies in particular;

- applying the experiential learning method that was implemented throughout the workshop, to create an efficient lighting design and a favorable learning environment where all participating groups can collaborate and benefit from such method;

- organizing international workshops in Egypt to promote the exterior lighting design and to expose students to others experiences;

- increasing the participation of students in international workshops as part of their training during undergraduate studies;

- promoting the idea of working in multi-cultural groups which helps in exchanging creative ideas as well as gaining social experiences;

- carrying out further research to conclude how to originate a creative lighting design and how to develop the lighting theme; and

- Investigating in details the technical aspects of the lighting design and how to connect them to the design aspects in a unified creative matrix.

\section{REFERENCES}

[1] Bloom, B., (1984) "Taxonomy of Educational Objectives: The Classification of Educational Goals. Handbook 1: Cognitive Domain”, Addison Wesley Publishing Company, Imprint of Pearson PLC, London.

[2] Clem, J., Mennicke, A., and Beasley, C., (2014): "Development and Validation of the Experiential Learning Survey”, Journal of Social Work Education, Volume 50, pp.490-506.

[3] Cornell, R., Johnson, C., and Schwartz, W., (2013): "Enhancing Student Experiential Learning with Structured Interviews", Journal of Education for Business, Volume 88, pp.136-146.

[4] Derevenskaia, O., (2014): "Active Learning Methods in Environmental Education of Students”, Procedia - Social and Behavioral Sciences 131, pp.101-104.

[5] Hanson, D., (2006): "Instructor's Guide to Process-Oriented Guided-Inquiry Learning", Pacific Crest, Lisle, IL.

[6] Herman, L., and Mandell, A., (2015): “Experiential Learnings Revised”, Journal of Learning for Development (JL4D), Volume 2, No. 1, pp.83-95

[7] Johnson, D., Johnson, R., and Smith, K., (1991) "Cooperative Learning: Increasing College Faculty Instructional Productivity", George Washington University, Graduate School of Education and Human Development, Washington, DC.

[8] Khodeir, L., (2015): "Forming a Constructivism Design Studio: Simulation of Real-life Architecture Experience on an Experimental Youth Workshop in Egypt", Journal of Engineering Sciences - Assiut University - Faculty of Engineering, Vol. 43 No. 1, pp.125 - 139

[9] Kowaltowski, D., Bianchi, G., and Teixeira de Paiva, V., (2010): "Methods that may Stimulate Creativity and their Use in Architectural Design Education", International Journal Technology and Design Education, Volume 20, Issue 4, pp.453-476.

[10] Parahakaran, S., (2017): "An Analysis of Theories Related to Experiential Learning for Practical Ethics in Science and Technology”, Universal Journal of Educational Research, Volume 5(6), pp.1014-1020.

[11] Sönmez, M., (2014): "The Role of Technology Faculties in Engineering Education", Procedia - Social and Behavioral Sciences, Volume 141, pp.35-44. 


\section{عملية إسترشادية موجهة للتطم التجريبي كأسلوب تدريس مبتكر في تعليم الإضاءة فى العمارة

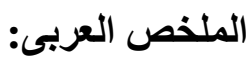

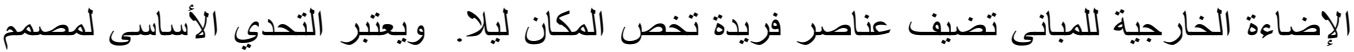

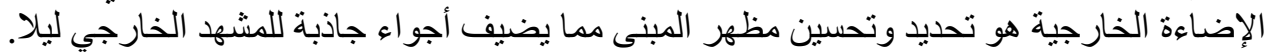

تهدف هذة الدراسة التربوية إلى تقييم تجربة تطبيق أسلوب "التعلم التجريبي" فى تعليم الإضلاءة التهاءة

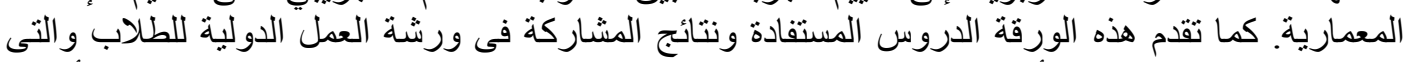

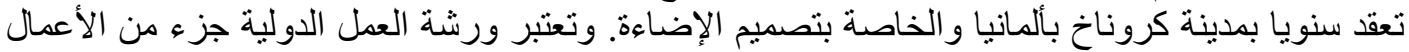

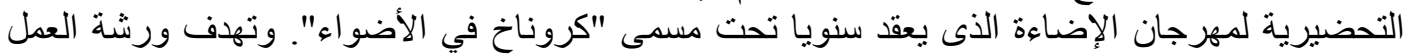
الدولية لتغطية الأجز اء النظرية والخبر الات العملية فى مجال الإضاءة الخارية الخارجية للمبانى، كما أنها تستهدف تدريب طلاب المرحلة الجامعية وكذلك طلاب مرحلة الدر اسات العليا.

لتحقيق الهدف من ورشة العمل، تم إتباع نهج "التعلم التجريبي" مع المشاركون حيث أن استخدام

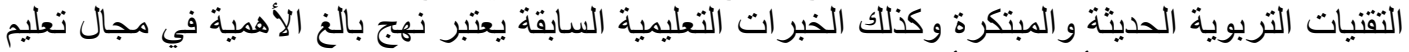

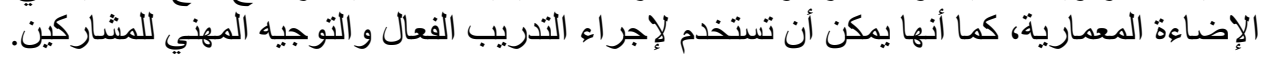

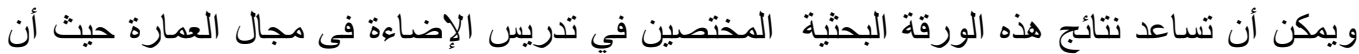



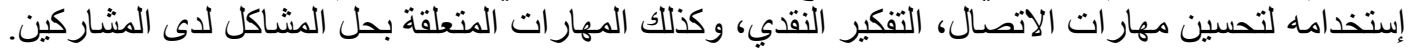

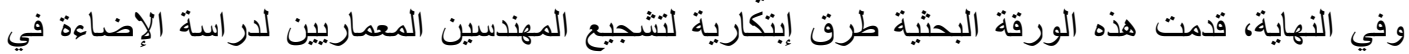
العمارة.

الإعلمات المفتاحية: تصميم الإضـاءة، تعليم الإضـاءة، التعلم التجريبي، عملية موجهة، التذريس المبتكر، الإضـاءة 